\title{
Descrição histológica de gônadas de traíra Hoplias malabaricus (Bloch) (Osteichthyes, Erythrinidae) da barragem do rio Gramame, Alhandra, Paraíba, Brasil
}

\author{
Débora K.S. Marques ${ }^{1}$ \\ lerecê de Lucena Rosa ${ }^{2}$ \\ Hélio de Castro B. Gurgel ${ }^{1}$
}

\begin{abstract}
Histological description of the gonads of the traira Hoplias malabaricus (Bloch) (Osteichthyes, Erythrinidae) from the Gramame River Reservoir, Alhandra, Paraíba, Brazil. The reproductive cycle of Hoplias malabaricus Bloch, 1794, was studied through histological preparations, based on 102 specimens collected in the Gramame reservoir, Paraiba State, from August 1993 to July 1994. Seven developmental stages were identified for the feminine gametes and five for the masculine gametes.
\end{abstract}

KEY WORDS. Hoplias malabaricus, Gramame reservoir, histology, gonads

Nos peixes, a dinâmica do processo reprodutivo e a viabilidade da prole refletem diretamente, ainda que não de maneira única, o funcionamento das suas gônadas (CHAVES \& VAZZOLER 1984). Considerando-se que cada espécie tem sua distribuição estabelecida por determinado conjunto de condições ecológicas, ela deve apresentar uma única estratégia reprodutiva e, para tanto, apresentar adaptações anatômicas, fisiológicas, comportamentais e energéticas específicas (VAZzOLER 1996). As variáveis do comportamento reprodutivo espelham a adaptação de determinado organismo às dificuldades impostas pelo meio ambiente e podem ser usadas como base para mecanismos de manutenção dos estoques. Assim, informações acerca dos processos reprodutivos são importantes e necessárias para subsidiar ações de manejo e conservação de espécies.

O rio Gramame, objeto do presente estudo, é o principal rio da Bacia Litoral Sul do Estado da Paraíba. Nasce ao norte do município de Pedras do Fogo, Paraíba, e deságua no Oceano Atlântico ao sul de Barreiras do Jacarapé, ocupando uma área total de $580 \mathrm{~km}^{2}$, entre o litoral e a zona da mata ao sul da capital da Paraíba ( $7^{\circ} 10^{\prime} 32^{\prime \prime}, 7^{\circ} 24^{\prime} 3^{\prime \prime}$ S e $\left.34^{\circ} 48^{\prime} 7^{\prime \prime}, 35^{\circ} 10^{\prime} 48^{\prime \prime} \mathrm{W}\right)$. Em 1977, foi represado tendo como objetivo o fornecimento de água para a cidade da grande João Pessoa.

Seu reservatório tem uma capacidade de $30.760 .000 \mathrm{~m}^{3}$, e abriga 14 espécies de peixes nativas, sujeitas às características do represamento das águas, à poluição química e à introdução do tucunaré, Cichla cf. ocellaris (TORELLI et al. 1997).

1) Departamento de Fisiologia, Universidade Federal do Rio Grande do Norte. Caixa Postal 15115, 59072-970 Natal, Rio Grande do Norte, Brasil.

2) Departamento de Ecologia e Sistemática, Univesidade Federal da Paraiba. 58059-900 João Pessoa, Paraiba, Brasil. 
A atividade pesqueira se desenvolve nos trechos de água doce e estuário do rio Gramame, destinando-se basicamente à subsistência. Uma das espécies mais utilizadas para fins de consumo na área é Hoplias malabaricus (Bloch, 1794), objeto do presente estudo, e conhecida popularmente como traíra.

Em Hoplias malabaricus, não é possivel a distinção do sexo ou dos seus estádios de maturação com base em características sexuais secundárias. Assim, a fim de caracterizar as fases do seu ciclo reprodutivo, são necessários estudos do desenvolvimento das gônadas em nível microscópico. No Brasil, os principais trabalhos anteriores acerca do ciclo reprodutivo desta espécie foram feitos por PAIVA (1974) e CARAMASCH et al. (1982), porém apenas o primeiro autor descreveu sucintamente a gametogênese masculina. No presente estudo, estão descritos a gametogênese da referida espécie, destacando cinco estágios de desenvolvimento dos gametas masculinos e sete estágios dos gametas femininos.

\section{MATERIAL E MÉTODOS}

Foram capturados 102 exemplares (50 machos e 52 fềmeas) de Hoplias malabaricus, entre agosto de 1993 e julho de 1994, utilizando-se redes-de-espera (1,5 e 6,0 cm entre nós), de arrasto (4,0 e 6,0 cm entre nós), tarrafas (2,0 cm entre nós) e anzóis de diversos tamanhos, na Barragem do Rio Gramame, Alhandra, distante $30 \mathrm{~km}$ da cidade de João Pessoa, Paraíba.

O sexo dos exemplares foi determinado por meio de uma incisão ventral mediana para exposição das gônadas. Porções medianas de aproximadamente $5 \mathrm{~mm}$ de espessura, de ovários e testículos em diferentes fases de desenvolvimento das gônadas, foram fixados em formolina a $10 \%$ e submetidas ao tratamento histológico pelas técnicas de Hematoxilina-Eosina (HE), Alcian Blue e Periodic Acid Schiff (PAS), seguindo metodologia de MiCHALANY (1990), previamente ajustada ao material deste estudo.

Os gametas foram classificados em estágios de desenvolvimento na linhagem ovogênica de acordo com o surgimento e/ou modificação de estruturas celulares e camadas foliculares, e afinidade tintorial dos componentes protoplasmáticos.

\section{RESULTADOS}

Através de cortes histológicos foram identificados sete estágios gonadais em fêmeas e cinco em machos.

\section{Fêmeas}

Ovogônia. Apresenta-se como a menor célula da linhagem ovogênica. Caracteriza-se por um núcleo grande, esférico e basófilo e por um citoplasma também basófilo. Esta célula pode ser encontrada solitária ou em cistos (Fig. la).

Ovócito I. Célula com citoplasma fortemente basófilo, e de contorno irregular; nesta fase, já se observa a presença do Corpo de Balbiani. Seu núcleo é esférico e bem definido, com grande quantidade de nucléolos dispostos perifericamente. A cromatina apresenta-se condensada em pequenos grumos, distribuídos por toda área do núcleo; há somente uma camada de células achatadas, como envoltório folicular (Fig. 1b). 

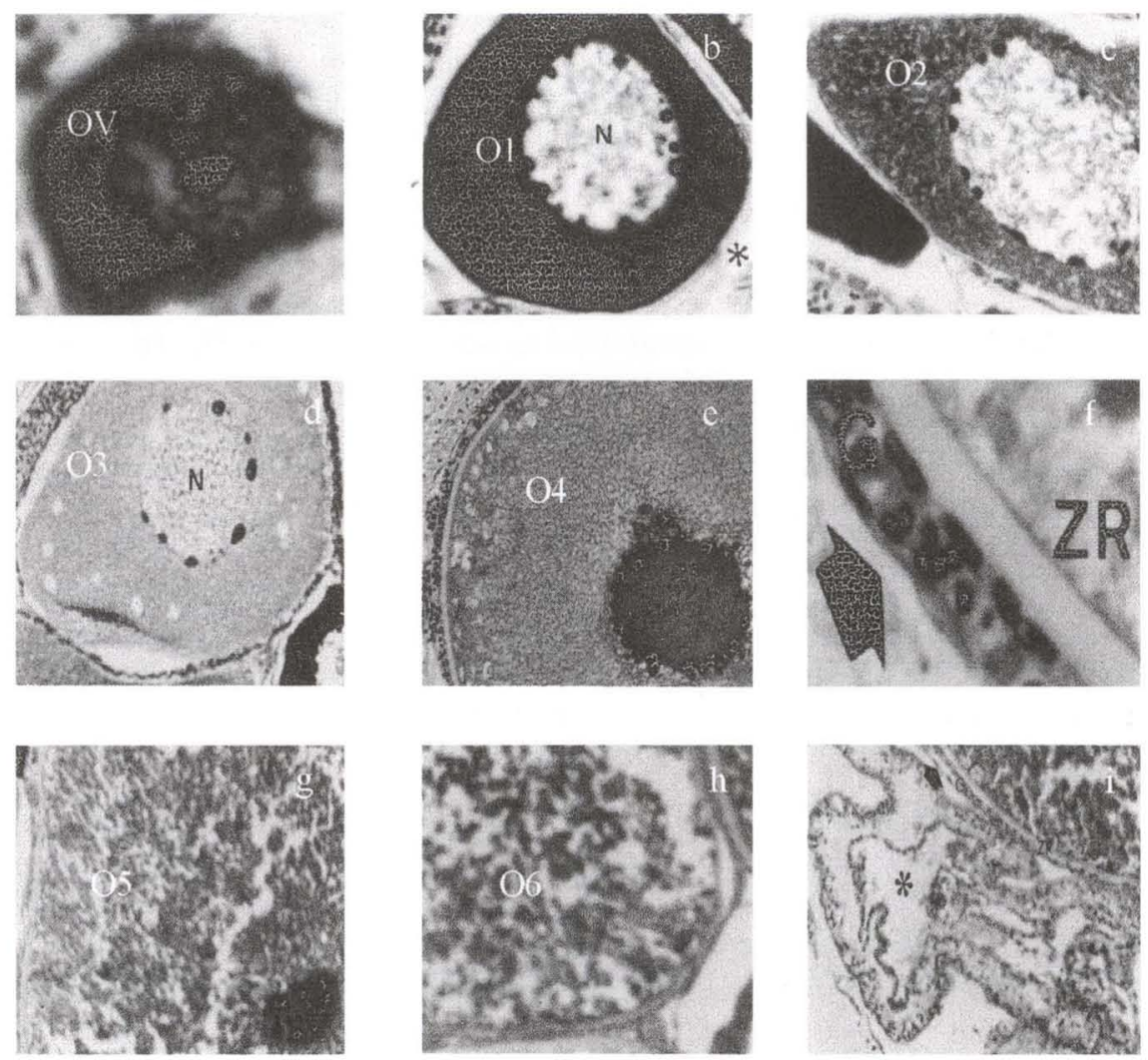

Fig. 1. (a) Ovogônia (OV); (b) ovócito 1 (O1), células foliculares (folículo vazio); (c) ovócito 2 (O2); (d) ovócito 3(O3); (e) ovócito 4 (O4). Detalhe mostrando as células foliculares da camada granulosa (G) e da teca (seta) e; (f) zona radiata (ZR); (g) ovócito 5 (O5); (h) ovócito 6 (O6); (i) folículo vazio. PAS.

Ovócito II. Nesta célula o núcleo mantém sua organização interna anterior, porém o citoplasma torna-se menos basófilo e apresenta contorno ainda irregular; o envoltório folicular continua composto por somente uma camada de células achatadas (Fig. 1c).

Ovócito III. O núcleo passa a ter contorno irregular, cuja carioteca emite projeções para o citoplasma, no interior das quais se abrigam os numerosos nucléolos. A cromatina permanece condensada em pequenos grumos, distribuídos por toda área do núcleo. O citoplasma torna-se menos basófilo. Alvéolos, em pequena quantidade, podem ser encontrados em qualquer região do citoplasma. Neste estágio a zona radiata torna-se evidente, bastante delgada e translúcida, envolvida por uma camada de células globosas e uma camada de células pavimentosas, compondo a granulosa e a teca, respectivamente (Fig. 1d).

Ovócito IV. Neste estágio, o núcleo mantém o contorno irregular com muitos nucléolos periféricos, mas agora apresenta-se basófilo com cromatina descondensada. O citoplasma torna-se acidófilo, e os alvéolos passam a ocupar a sua porção 
cortical. Nesta fase, aparecem alvéolos, preenchidos por material acidófilo, e grânulos de vitelo (Fig. 1e). O folículo, nesta célula, é composto pela zona radiata, mais espessa que na fase anterior, seguida da granulosa como camada única de células achatadas e duas outras camadas de células globosas menores. A teca aparece aqui como uma camada simples de células pavimentosas (Fig. 1f).

Ovócito V. O núcleo mantém o arranjo interno da fase anterior. O citoplasma, porém, tem sua acidofilia acentuada e apresenta-se completamente ocupado por grânulos de vitelo, mas, ainda com alvéolos na sua porção cortical (Fig. lg). A zona radiata e as células foliculares permanecem como na fase anterior.

Ovócito VI. Neste estágio não visualizamos o núcleo da célula em nossas preparações histológicas. O citoplasma, fortemente acidófilo, é completamente ocupado por grânulos de vitelo e desprovido de alvéolos corticais (Fig. 1h). O folículo não apresenta modificações em sua estrutura, em relação ao ovócito $\mathrm{V}$.

Folículo vazio. Após a saída do ovócito maduro, permanecem no estroma ovariano as células da camada granulosa e da teca. Entretanto, a primeira camada da granulosa, que antes era composta por células achatadas, agora apresenta células globosas. A teca não sofre nenhuma mudança com a liberação do ovócito (Fig. 1i).

\section{Machos}

Espermatogônias. São as maiores células da linhagem espermatogênica. Encontram-se solitárias ou em cistos. Seu citoplasma apresenta pouca afinidade tintorial. Um núcleo esférico grande é evidente, com cromatina condensada em grumos localizados perifericamente. Há um único nucléolo grande e central (Fig. 2a).

Espermatócito I. Encontra-se em cistos. Seu citoplasma apresenta pouca afinidade tintorial. Neste estágio, o núcleo mantém a cromatina condensada em grumos localizados perifericamente. Porém, agora são visíveis um ou mais nucléolos (Fig. 2b).

Espermatócito II. Encontra-se em cistos. Seu citoplasma apresenta pouca afinidade tintorial. Nesta célula, o núcleo apresenta a cromatina condensada em toda área do núcleo ou voltada para um dos pólos, numa formação de meia-lua. Neste estágio não são observados nucléolos (Fig. 2c).

Espermátide. Encontra-se em cistos. Seu citoplasma não é visível em nossas preparações. Neste estágio, a cromatina apresenta-se condensada, dando ao núcleo um aspecto uniforme (Fig. 2d).

Espermatozóides. Representam as menores células na linhagem espermatogênica. São encontradas formando cistos ou livres na luz do túbulo seminífero. Possuem núcleo basófilo e esférico. Seus flagelos não foram visíveis em nossas preparações histológicas (Fig. 2e).

\section{DISCUSSÃO}

A ovogênese envolve uma série de modificações nos níveis nuclear, citoplasmático e folicular, que resulta em um gameta fertilizável dotado de estruturas que refletem a estratégia reprodutiva e a importância dos estudos desses eventos para o enriquecimento do conhecimento da biologia de uma determinada espécie. 

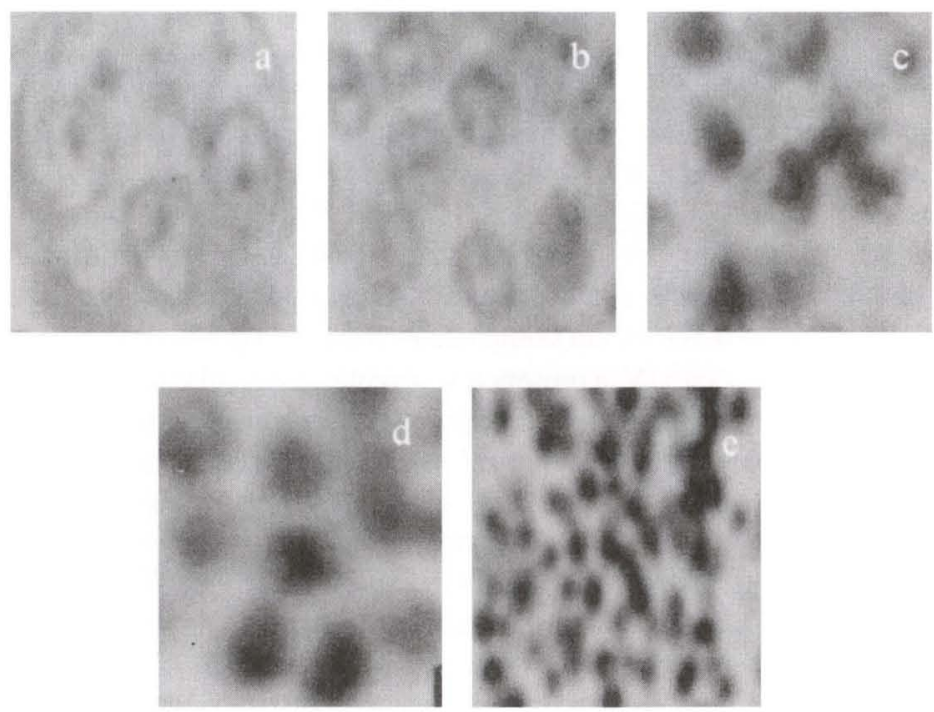

Fig. 2. (a) Espermatogônias; (b) espermatócitos I; (c) espermatócitos II; (d) espermátides; (e) espermatozóides. (PAS).

Em Hoplias malabaricus, as ovogônias corresponderam a descrição feita para peixes teleósteos por VAZzoler (1996), que denominou esta fase inicial de "células germinativas jovens ou cromatina-nucleolar". Entretanto, talvez devido às possibilidades de definição oferecidas pelas técnicas utlizadas nesse estudo, não visualizam-se nesta fase o nucléolo central observado pela citada autora.

O padrão observado neste estudo para o núcleo do ovócito I foi também descrito para Hoplias malabaricus por PAIVA (1974) e para Rhamdia hilarii Valenciennes, 1840 por NARAHARA et al. (1985). VAZZOLER (1996), chamou esta fase de "ovócitos do estoque de reserva" visto que, segundo a autora, é deste grupo que irão originar-se as populações celulares que iniciar a vitelogênese.

A forte basofilia do citoplasma no estágio ovócito I, também verificada por NARAHARA et al. (1985) para Rhamdia hilarii, ocorre, segundo MATKOVIC \& PISANÓ (1989a), devido à presença de grande número de proteínas e ácidos nucléicos. No citoplasma de alguns ovócitos neste estágio, visualizamos o Núcleo Vitelínico ou Corpo de Balbiani, cuja origem, morfologia e função são muito discutidas (NARAHARA et al. 1985). A presença do Corpo de Balbiani no estágio ovócito I também foi observada por ALEXANDRINO et al. (1988) e WALLACE (1978). MATKOVIC \& PISANÓ (1989a) citam, para H. malabaricus, o Corpo de Balbiani no estágio final deste estágio. Entretanto, PAIVA (1974) não registrou esta estrutura para a mesma espécie.

A fase celular denominada ovócito II, caracterizada neste estudo, não corresponde a nenhuma descrição anterior para a mesma espécie. A sua identificação como fase distinta deveu-se a observação da perda acentuada da basófilia pelo citoplasma, em relação a fase anterior. 
As características descritas para o núcleo do ovócito III, em nosso estudo, também foram observadas por NARAHARA et al. (1985) em Rhamdia hilarii. Nesta fase, os alvéolos, sem afinidade tintorial, espalhados pelo citoplasma do ovócito III, também foram observados por PAIVA (1974) para Hoplias malabaricus. Entretanto, CUSSAC \& MAGGEZE (1986), estudando a espécie Rhamdia sapo Quoy \& Gaimard, 1824 relatam o aparecimento destas estruturas já no estágio imediatamente após ao de ovogônia. O que sugere que nesta espécie a vitelogênese inicia-se mais cedo no desenvolvimento ovocitário, em comparação Hoplias malabaricus.

No estágio ovócito IV, a presença de alvéolos e vesículas de vitelo preenchidas por grânulos PAS + na porção cortical, observada neste trabalho, foi também verificada por MATKOVIC \& PISANÓ (1989a) para H. malabaricus, e em Geophagus brasiliensis Quoy \& Gaimard, 1824 por BARBIERI et al. (1981). A redução da basofilia do citoplasma, neste estágio, pode ser em parte devida à dispersão citoplasmática imposta pela presença das vesículas de vitelo (MATKOVIC \& PISANÓ 1989a).

Segundo VAZZOLER (1996), o estágio ovócito IV corresponde à fase de "vitelogênese lipídica e protéica", na qual há deposição de proteína na forma de plaquetas acidófilas, e que se caracteriza por um acelerado crescimento citoplasmático.

De acordo com WEST (1990), o aparecimento de vesículas de vitelo caracteriza o estágio ovócito IV, que é por ele denominado "estágio de formação de vesículas de vitelo ou de alvéolos corticais". O autor destaca ainda que o conteúdo das vesículas não é vitelo propriamente, visto que não serve como recurso nutritivo para o futuro embrião.

A composição das vesículas corticais, zona pelúcida e células foliculares varia em peixes teleósteos. Estas variações podem refletir diferentes funções destes componentes na dinâmica da ovogênese (BAZzolı \& Rizzo 1990). Estes autores consideram ainda que a diversidade no conteúdo citoquímico das vesículas corticais de espécies de teleósteos de água doce parece ser específica, desta forma indicando papel funcional específico na fertilização.

O estágio ovócito $\mathrm{V}$ de desenvolvimento ovocitário é definido como sendo a fase de crescimento por BOWERS \& HOLLIDAY (1961). WEST (1990) explica que neste estágio, denominado pelo autor de "estágio vitelogênico", os grânulos de vitelo podem manter sua integridade ao longo do crescimento ovocitário, ou fundirem-se eventualmente, formando uma massa contínua de vitelo fluido, que dá aos óvulos a sua transparência característica. Neste trabalho, observou-se que o ovócito $\mathrm{V}$ apresenta citoplasma completamente preenchido por grânulos de vitelo, mas ainda com alvéolos na sua porção cortical, fato este também observado para a mesma espécie por MATKOVIC \& PISANÓ (1989b), que o explicam como conseqüência do incremento do volume de vitelo no ovócito.

O ovócito VI, conforme observado no presente trabalho, possui seu citoplasma completamente ocupado por grânulos de vitelo, como já observado para a mesma espécie por MATKOVIC \& PISANÓ (1989b). Neste estágio não observou-se núcleo celular. Segundo MATKOVIC \& PISANÓ (1989b) isto ocorre devido à ruptura do núcleo, cujo conteúdo se mistura ao citoplasma. Isso denota uma existência temporalmente muito limitada para a célula, que, no auge de sua funcionalidade, é desprovida de núcleo. 
Durante o desenvolvimento das células germinativas, observa-se que ocorrem modificações nas suas camadas envoltórias e, de acordo com CARAMASCHI et. al. (1982) é principalmente nestas que as variações com o decorrer do desenvolvimento parecem manifestar-se em Hoplias malabaricus. No presente estudo, distingui-se três componentes do envoltório folicular: zona radiata, camada granulosa e teca.

Nas primeiras fases de desenvolvimento, I e II, o envoltório folicular é representado por uma camada única de células pavimentosas. Fato também observado por BAzZoLI \& Rizzo (1990) para dez espécies de teleósteos brasileiros, mas, segundo BARBIERI et al. (1981), ausente em Geophagus brasiliensis.

Verificou-se na fase III o aparecimento da zona radiata, chamada córion por BOWERS \& HOLLIDAY (1961) e também encontrada neste estágio em Geophagus brasiliensis (BARBIERI et al. 1981). Esta camada mostra-se, bastante delgada e translúcida, composta por uma substância amorfa, PAS +, como indicado por CUSSAC \& MAGGESE (1986), modificando-se em espessura, somente, ao longo do amadurecimento da célula germinativa. No presente estudo, o aparecimento da zona radiata se deu ao mesmo tempo que o das células da camada granulosa, confirmando os registros feitos por NARAHARA et al. (1985), para Rhamdia hilarii e por BOWERS \& Holliday (1961) para Clupea harengus Hubbs, 1888.

NARAHARA et al. (1985) sugere que, devido ao seu caráter PAS +, a zona radiata é de natureza polissacarídica. Segundo WALLACE \& SELMAN (1981) e NARAHARA et al. (1985), a formação da zona radiata (ou zona vitelina) se deve ao ovócito. Entretanto, BowERS \& HOLLIDAY (1961) atribuem este evento às células da granulosa.

Segundo WEST (1990) o aparecimento da zona radiata pode ocorrer em diferentes fases da ovogênese, variando entre as espécies.

Alguns autores, como MatKovic \& PisAnó (1989b), BAzzoli \& Rizzo (1990) e Rizzo \& BAzzoli (1991) atribuíram natureza glicoprotéica para os glóbulos de vitelo e zona radiata. Além disso, mencionaram a presença de uma segunda camada da zona radiata, denominada zona externa, observada também em Rhamdia hilarii por NARAHARA et al. (1985). Entretanto, considerando as possibilidades fornecidas pelas técnicas utilizadas em nosso trabalho, observou-se em Hoplias malabaricus que a zona radiata apresenta-se como uma única camada, como também foi descrito para a mesma espécie por PAIVA (1974), o que sugere que nesta espécie a zona radiata é verdadeiramente bem simples.

O padrão descrito em nosso estudo, para o folículo das células nas fases III, IV e $\mathrm{V}$, no qual a camada folicular é composta por camadas de células distintas (achatadas e globosas, compondo a camada granulosa) e uma camada de células pavimentosas, denominada teca, não foi observado em trabalhos anteriores acerca de Hoplias malabaricus.

BAZZOLI \& RIZZO (1990) observaram a camada granulosa composta somente por células cubóides em Serrasalmus brandtii Reinhardt, 1874, Acestrorhyncus britskii Menezes, 1969 e Schizodon knerii Steindachner, 1875 e apenas por células escamosas em outras espécies por eles estudadas. NARAHARA et. al. (1988) obser- 
varam que a camada granulosa de Rhamdia hilarii apresenta células que inicialmente são achatadas e tornam-se altas ao longo do desenvolvimento, como também observado em Geophagus brasiliensis (BARBIERI et al. 1981).

BAzzoli \& Rizzo (1990) registraram para Acestrorhyncus britskii e Schizodon knerii, que as células foliculares são PAS+, estes autores sugerem que, por este caráter, estas podem conter glicoproteína neutra. A mesma característica PAS + foi observada no presente estudo para as células da granulosa de Hoplias malabaricus. Entretanto, observa-se que as células globosas desta camada apresentam coloração mais intensa que as células achatadas, o que pode sugerir uma maior participação destas no processo de acumulação de vitelo pelo ovócito durante seu desenvolvimento.

Em observações feitas em nível de microscopia eletrônica NARAHARA et al. (1985) à medida que as células foliculares tornam-se mais altas, observa-se a formação de microvilos que se projetam no interior da zona radiata, em direção ao ovócito. Assim, segundo os autores, essas células possivelmente estão envolvidas no processo de síntese durante o desenvolvimento dos gametas, embora não se conheça sua exata função.

Segundo Bowers \& Holliday (1961) a camada granulosa é resultado da migração de células do tecido conjuntivo, e a partir desse processo de formação da camada granulosa é que começam a série de transformações internas do ovócito. Assim, afirmam os autores, o desenvolvimento completo dos ovócitos depende das propriedades das células da camada granulosa.

A constituição da camada granulosa, observada no presente trabalho, sugere que esta, além de ser ativa no intercâmbio de material com o ovócito, pode possivelmente atuar na formação de envoltórios adicionais.

Neste estudo verificou-se que a teca é constituída por camada única de células pavimentosas, e assim se mantém até o final da ovogênese.

Em Hoplias malabaricus, o estroma dos testículos é constituído por tecido conjuntivo de aspecto fibroso frouxo, onde localizam-se agrupamentos de células da linhagem espermatogênica, denominados cistos. Cada cisto é composto por células na mesma fase de desenvolvimento, assim como foi descrito para Geophagus brasiliensis (BARBIERI et al. 1981), Rhamdia hilarii (NARAHARA et al. 1985) e Prochilodus scrofa Steindachner, 1881 (AlEXANDRINo et al. 1985). Entretanto, também encontramos espermatogônias e espermatozóides isolados, como registrado em outras espécies, como Geophagus brasiliensis (BARBIERI et al. 1981) e Rhamdia hilarii NARAHARA et al. (1985).

As espermatogônias de Hoplias malabaricus observadas no presente estudo apresentam características semelhantes àquelas mencionadas para a mesma espécie por Paiva (1974) e em Prochilodus scrofa por AleXANDRINO et al. (1985).

$\mathrm{Na}$ fase espermatócito I, que possui as mesmas características da célula denominada espermatogônia secundária por BowERS \& HOLLIDAY (1961), o núcleo ainda apresenta cromatina condensada em grumos periféricos. Isto também foi observado em Hoplias malabaricus por PAIVA (1974), que descreveu quatro estágios de desenvolvimento gamético, sendo que as fases espermatócito I e II, descritas 
em nosso estudo, são agrupadas por aquele autor como apenas uma fase (espermatócito).

No nosso estudo, a fase espermatócito II foi definida por apresentar o núcleo com cromatina condensada, dando ao mesmo um aspecto uniforme, ou voltada para um dos pólos, numa formação de meia-lua.

Nas observações deste artigo encontrou-se na fase espermatócito I a presença de mais de um nucléolo. O espermatócito II Hoplias malabaricus segue o mesmo padrão descrito em Clupea harengus por BowERS \& HOLLIDAY (1961), que sugerem que este estágio corresponda a uma fase de descanso. A disposição periférica da cromatina, nesta fase, também foi observada em Prochilodus scrofa por ALEXANDRINO et al. (1985).

Em nosso estudo, as espermátides apresentam características que corroboram as observações feitas por autores como BowERS \& HollidAY (1961), PAIVA (1974) e ALEXANDRINO et al. (1985).

Após o estágio de espermátide, registrou-se a presença de espermatozóides. Esta fase, segundo ALEXANDRINO et al. (1985), é resultado de uma metamorfose sofrida pelas espermátides. Observou-se células de Sertoli estreitamente ligadas aos cistos espermatogênicos, envolvendo-os. Segundo Silva \& GodinHo (1989), elas desempenham o papel de barreira de proteção. De acordo com BowERS \& HOLLIDAY (1961), são possivelmente responsáveis pela alimentação das células germinativas.

\section{CONCLUSÕES}

Os resultados apresentados mostram pela primeira vez que o folículo ovocitário na espécie estudada possui uma camada granulosa composta por dois tipos distintos de células, diferentemente das primeiras descrições que mostravam somente um tipo de célula para esta camada. As características de coloração PAS+ apresentadas pela camada granulosa sugerem que as células globosas são mais participantes, do que as células achatadas no processo de acumulação de vitelo pelo ovócito durante seu desenvolvimento.

AGRADECIMENTOS. A Dra. Elizabeth Romagosa, pesquisadora do Instituto de Pesca, de São Paulo, pelas sugestões que enriqueceram o presente trabalho.

\section{REFERÊNCIAS BIBLIOGRÁFICAS}

Alexandrino, A.C.; M.T. Phian \& E.F.G. Pinileiro. 1988. Caracterização macroscópica e microscópica das gônadas do curimbatá, Prochilodus scrofa (Steindachner, 1881), durante o ciclo reprodutivo. Bol. Zool. Univ. São Paulo 9 (1): 59-175.

BARbieri, M.C.; G. BARbieri \& M. DE A. Marins. 1981. Sobre a anatomia e histologia de ovário de Geophagus brasiliensis (Quoy \& Gaimard, 1824) na Represa do Lobo, Estado de São Paulo. Rev. Brasil. Biol. 41 (1): 163-168.

BAzzoli, N. \& E. Rizzo. 1990. A comparative cytological and cytochemical study of the oogenesis in ten brazilian teleost fish species. Eur. Arch. Biol. 101: 399-410.

Bowers, A.B. \& F.G.T. HollidAY. 1961. Histological changes in the gonad associated with the reproductive cycle of the herring (Clupea harengus L.). Mar. Res., Scotland, 5: 3-16.

Revta bras. Zool. 17 (3): 573 - 582, 2000 
CAramaschi, E.P.; H.M. Godinho \& F. Forest. 1982. Reprodução de Hoplias malabaricus (Bloch, 1794) (Teleostei, Erythrinidae) na represa do Rio Pardo (Botucatu, SP). I. Histologia e escala de maturação do ovário. Rev. Brasil. Biol. 42 (3): 635-640.

Chaves, P. DE T. DA C. \& A.E.A. De M. Vazzoler. 1984. Aspectos biológicos de peixes amazônicos. I. Anatomia microscópica de ovários, escala de maturidade e tipo de desova das espécies do gênero Semaprochilodus. Rev. Brasil. Biol. 44 (3): 347-359.

CusSAC, V.E. \& M.C. MAGgeSE. 1986. Oogenesis in Rhamdia sapo (Pisces, Pimelodidae) stages of the oocyte, egg's envelopes and affects of the human chorionic gonadotropin. Rev. Brasil. Biol. 46 (1): 139-147.

MatKovic, M. \& A. Pisanó. 1989a. Oogenesis and ovulation in normal conditions or induced by homologous hypophysis in Hoplias malabaricus (Pisces, Erythrinidae). Rev. Brasil. Biol. 49 (1): 203-212.

- 1989b. Final maturation and ovulation provoked by supply of homologous hypophysis in Hoplias malabaricus (Pisces, Erythrinidae). Rev. Brasil. Biol. 49 (1): 213-220.

Michalany, J. 1990. Técnica histológica em anatomia patológica com instruções para o cirurgião, enfermeira e citotéenico. São Paulo, Edusp, XVI+240p.

Narahara, M.Y.; M.A. Basit.e-Martins; H.M. Godinho \& M.N. Cipóll.t. 1988. Escala de maturidade, época de reprodução e influência de fatores abióticos sobre o desenvolvimento gonadal de Rhamdia hilarii (Valenciennes, 1840). Bol. Inst. Pesca. 15 (2): 201-211.

Narahara, M.Y.; M.H. Godinho \& E. Romagosa. 1985. Estrutura da população da reprodução de Rhamdia hilarii (Valenciennes, 1840) (Osteichthyes, Siluriformes, Pimelodidae). Bol. Inst. Pesca. 12 (3): 123-137.

PAIVA, M.P. 1974. Crescimento, alimentação e reprodução da traíra, Hoplias malabaricus (Bloch), no Nordeste brasileiro. Fortaleza: Universidae Federal do Ceará, Mimeografado.

Rizzo, E. \& N. B^zzolı. 1991. The zona pellucida of the brazilian white piranha, Serrasalmus brandtii Reinhardt, 1874 (Pisces, Characidae): a cytological and cytochemical study. Funcional and Developmental Morfology. 1 (4): 21-24.

Silva, M. \& H.P. Godinho. 1989. Barreira hemotesticular em Oreochromis niloticos (Peixe, Teleósteo). Rev. Bras. Ciên. Morfol., São Paulo, 6 (1).

TORElli, J.; I.L. Rosa \& T. WATANABE. 1997. Ictiofauna do Rio Gramame, Paraíba, Brasil. Iheringia, sér. Zool., 82: 67-73.

VAZZOLER, A.E.A.M. 1996. Biologia da reprodução de peixes teleósteos: teoria e prática. São Paulo, Eduem, SBI, 169p.

WALLACE, R.A. 1978. Oocyte growth in non mammalian vertebrates, p. 496-502. In: R.E. JoNES. The vertebrates ovary. New York, Plenum Press, 502p.

Wallace, R.A \& K. Selman. 1981. Cellular and dynamic aspects of oocyte growth in teleosts. Amer. Zool. 21: 325-343.

WESt, G. 1990. Methods of assessing ovarian development in fishes: a review. Aust. Jour. Mar. Freshwater. Res. 41: 199-222.

Recebido em 08.X.1998; aceito em 25.V.2000 